Article

\title{
Optimized Extraction of Phenylpropanoids and Flavonoids from Lemon Verbena Leaves by Supercritical Fluid System Using Response Surface Methodology
}

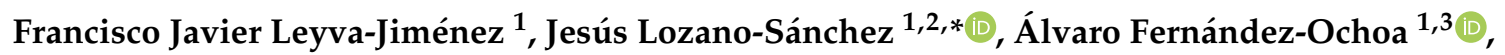 \\ María de la Luz Cádiz-Gurrea 1,3,*(D), David Arráez-Román 1,3,+ (iD) \\ and Antonio Segura-Carretero ${ }^{1,3,+}$ \\ 1 Functional Food Research and Development Center, Health Science Technological Park, \\ Avenida del Conocimiento s/n, E-18016 Granada, Spain; jleyva@cidaf.es (F.J.L.-J.); \\ alvaroferochoa@ugr.es (Á.F.-O.); darraez@ugr.es (D.A.-R.); ansegura@ugr.es (A.S.-C.) \\ 2 Department of Food Science and Nutrition, University of Granada, Campus of Cartuja, 18071 Granada, Spain \\ 3 Department of Analytical Chemistry, Faculty of Sciences, University of Granada, Fuentenueva s/n, \\ E-18071 Granada, Spain \\ * Correspondence: jesusls@ugr.es (J.L.-S.); mluzcadiz@ugr.es (M.d.l.L.C.-G.); Tel.: +34-958-240781 (J.L.-S.) \\ $\dagger$ These authors are joint senior authors on this work.
}

Received: 31 May 2020; Accepted: 6 July 2020; Published: 14 July 2020

check for updates

\begin{abstract}
The aim of this work was to optimize the recovery of phenolic compounds from Lippia citriodora using supercritical fluid extraction (SFE). To achieve this goal, response surface methodology based on a $2^{3}$ central composite design was used to evaluate the effects of the following experimental factors: temperature, pressure and co-solvent percentage. The effects of these variables on the extraction yield and total polar compound contents were evaluated. With respect to the phytochemical composition, an exhaustive individual phenolic compound quantitation was carried out by HPLC-ESI-TOF-MS to analyze the functional ingredients produced by this system design. To the best of our knowledge, this is the first time that a standardized supercritical fluid process has been developed to obtain functional ingredients based on phenolic compounds from L. citriodora in which the individual compound concentration was monitored over the different SFE conditions. The results enabled the establishment of the optimal technical parameters for developing functional ingredients and revealed the main factors that should be included in the extraction process control. This functional food ingredient design could be used as a control system to be applied in nutraceutical and functional food production industry.
\end{abstract}

Keywords: Lippia citriodora; supercritical fluid extraction; HPLC-ESI-TOF-MS; central composite design; response surface methodology

\section{Introduction}

In recent decades, the prevalence of several diseases such as obesity and diabetes has increased, causing high morbidity and premature mortality and greatly increasing health costs. Consequently, researchers have focused their investigations on the study of alternative treatments to prevent these diseases and to improve human health. In this sense, botanical sources have been claimed to provide beneficial properties related to several physiological disorders. For these reasons, in the last few years, researchers have focused on the challenge of the extraction of bioactive compounds from plants in order to increase the nutritional value of food products [1]. However, the amounts of compounds that 
are contained in the natural sources, even after some extraction procedures, are usually less than those needed to provide beneficial effects in the organism. Furthermore, different aspects may determine the retrieval of these bioactive compounds. Hence, it is necessary to evaluate the extraction method and the influence of each extraction parameter to discern the effectiveness of the process in terms of extract composition and extraction yield, since both variables can have a great influence in the balance of economic costs and profits.

Advanced extraction technologies have been claimed to be efficient alternatives when compared with conventional extraction methods in terms of their solvents (typically using GRAS (generally recognized as safe) solvents), time consumption, selective extraction and costs, enabling their utilization in developing functional food ingredients. All these characteristics result in a decreased environmental impact; thus, they are considered to be environmentally friendly techniques [2,3]. Indeed, supercritical fluid extraction (SFE) has been receiving growing interest as a sustainable technology which can be used without organic solvents [4] to revalorize food by-products [5,6] or extract specific phytochemicals $[7,8]$. SFE is an extraction process where analytes are dissolved in a supercritical fluid, which could be considered either as expanded liquid or compressed gas. Thus, it has liquid-like solvent power and gas-like diffusivity, giving it special properties that are useful in the recovery of valuable compounds and enabling a selective extraction of compounds through modifying the density and viscosity of the solvents used [9]. The most used supercritical fluid is $\mathrm{CO}_{2}$ since it is a nontoxic, nonflammable and cheap solvent. $\mathrm{CO}_{2}$ has a critical point of 73.8 bar and $31.1^{\circ} \mathrm{C}$, allowing the experiments to be run at room temperature; this is in contrast with other solvents such as water $\left(218.3\right.$ bar and $\left.347^{\circ} \mathrm{C}\right)$ or methanol $\left(79.8\right.$ bar and $239^{\circ} \mathrm{C}$ ). In addition, it is easily removable from the extract under atmospheric conditions. It is widely used to extract lipophilic compounds since $\mathrm{CO}_{2}$, due to its structure, is a nonpolar solvent that has a low capability of dissolving polar compounds. In order to recover more polar compounds such as flavonoids, procyanidins, purines or hydrophilic vitamins, $\mathrm{CO}_{2}$ is commonly used in combination with polar GRAS modifiers (i.e., ethanol) which would serve to enhance the extraction of polar compounds based on the formation of hydrogen bonds and the dipole-dipole or dipole-induced-dipole interactions between co-solvent and the analytes [10]. According to several reports, the addition of co-solvent may positively affect the extraction of phenolic compounds [11-13]. Consequently, SFE can be applied to recover phenolic compounds from botanical sources.

Lippia citriodora, commonly known as lemon verbena, is a plant that is native to South America and has traditionally been used to alleviate fever or stomachache. Recent studies have also attributed anti-inflammatory, antibacterial and anti-obesogenic properties to several phytochemicals in its composition, such as verbascoside or luteolin 7-diglucuronide [14-16], revealing this plant to be an interesting natural source of functional ingredients for the treatment of several disorders. Although the use of other advanced extraction methods to extract phytochemicals of lemon verbena has been previously reported $[17,18]$, no research has focused on the recovery of polar compounds of lemon verbena by SFE. Therefore, the development of an SFE process to recover bioactive compounds from lemon verbena would be of interest to producers, as such compounds could be used in developing functional food.

The purpose of this work was to develop, for the first time, an SFE process to optimize the retrieval of bioactive constituents from lemon verbena leaves; the bioactive constituents considered are mainly phenylpropanoids and flavonoids and may be used as functional ingredients. To achieve that goal, response surface methodology (RSM) based on a $2^{3}$ central composite design (CCD) model to evaluate the effect of independent factors on the recovery of bioactive phenols was applied. The combination of this extraction system with an analytical HPLC-ESI-TOF-MS platform was used to determine the extraction variables which have relevant effects on the extraction procedures so that the recovery of bioactive compounds from lemon verbena leaves can be maximized. 


\section{Materials and Methods}

\subsection{Reagents}

All reagents used in this work were at least of analytical reagent grade and used as received. SFE experiments were performed using $\mathrm{CO}_{2}$ and ethanol as modifier. Solvents were purchased from Air Product and Chemicals (Allentown, PA, USA) and VWR chemicals (Radnor, PA, USA). Ottawa sand was provided by Fisher Scientific (Leicestershire, UK). Glass wool was acquired from Sigma-Aldrich (Steinhemin, Germany). LC-MS-grade acetonitrile was purchased from Fisher chemicals (Waltham, MA, USA) and double-deionized water (conductivity of $<18.0 \mathrm{M} \Omega$ ) was obtained using a Milli-Q system acquired from Millipore (Bedford, MA, USA). Formic acid was purchased from Sigma-Aldrich (Steinheim, Germany). Apigenin, loganic acid, kaempferol 3-glucoside, quercetin, and verbascoside were purchased either from Fluka, Sigma-Aldrich (Steinheim, Germany) or Extrasynthese (Genay Cedex, France).

\subsection{Plant Material}

Lemon verbena leaves were provided by Monteloeder (Alicante, Spain). Leaves were milled using a ZM200 ultracentrifugal grinder (Retsch GmbH, Haan, Germany) with a 12-tooth rotor and 1-mm mesh sieve. The material was kept at room temperature and protected from light until extraction.

\subsection{Supercritical Extraction Procedures}

SFE was carried out with a Waters Prep SFE 100 Supercritical Fluid Extraction System (Waters, TharSFC, Thar Technologies Inc., Pittsburgh, PA, USA) equipped with $\mathrm{CO}_{2}$ and co-solvent pumps (model P-50), an automated back pressure regulator, low and high pressure heating exchangers, a pressurized extraction vessel $(100 \mathrm{~mL})$ and pressurized collection vessels. The SFE system was connected to an Accel 500 LC chiller produced by Thermo Scientific (TharSFC, Thar Technologies, Inc., Pittsburgh, PA, USA). Ground leaves were introduced into the extraction vessel by mixing $10 \mathrm{~g}$ of sample with $20 \mathrm{~g}$ of Ottawa sand and loaded this mixture into the stainless steel extraction cell. In order to prevent sample projection, glass wool was added to the top and the bottom of the extraction vessel. Experiments were conducted with the use of the Thar Instruments Process Suit software (Waters), selecting the following technical parameters: dynamic mode total time of 90 min and total solvent mass flow rate of $30 \mathrm{~g} / \mathrm{min}$. Since different percentages of co-solvent were used to optimize the extraction process, the $\mathrm{CO}_{2}$ and co-solvent mass flow rates over the different runs were introduced in the software according to the experimental design described below. As a result, the $\mathrm{CO}_{2}$ and co-solvent mass flow rates used were from 24.9 to $28.5 \mathrm{~g} / \mathrm{min}$ and from 1.5 to $5.1 \mathrm{~g} / \mathrm{min}$, respectively. After the extraction process, co-solvent was immediately evaporated using a rotary evaporator (Buchi R210, Flawil, Switzerland), and dried extracts were stored at $-20^{\circ} \mathrm{C}$ until HPLC analysis.

\subsection{Design of Experiments}

Response surface methodology (RSM) was used to evaluate the effect of SFE parameters on retrieval and yield of phenolic compounds. For this purpose, a CCD model with two axes, four central points and three levels $(-1,0,1)$ for each independent variable was applied: (a) temperature, 40, 50 and $60{ }^{\circ} \mathrm{C}$; (b) pressure, 150, 275 and 400 bar; and (c) co-solvent percentage, 7, 11 and 15\%. This model procured a total of 18 experiments which were conducted in a randomized order (Table 1). Finally, the bioactive compound contents in extracts as determined by HPLC-ESI-TOF-MS and the extraction yield were response variables. The extraction yield of each procedure was calculated considering the weight of dried extract and the amounts of lemon verbena used in the procedure (Equation (1)):

$$
\text { Yield }(\%)=\frac{\text { Weight of dried extract }(g)}{\text { Weight of dried leaves used }(g)} \times 100
$$


Table 1. Experimental values of central composite design (CCD) factors.

\begin{tabular}{ccccccc}
\hline & & \multicolumn{5}{c}{ Coded Levels } \\
\cline { 3 - 6 } Symbols & Factors & $\mathbf{- \alpha}$ & $\mathbf{- 1}$ & $\mathbf{0}$ & $\mathbf{+ 1}$ & $\mathbf{+} \boldsymbol{\alpha}$ \\
\cline { 3 - 7 } & & \multicolumn{5}{c}{ Experimental Levels } \\
\hline $\mathbf{Z 1}$ & Temperature $\left({ }^{\circ} \mathrm{C}\right)$ & 36 & 40 & 50 & 60 & 64 \\
$\mathbf{Z 2}$ & Pressure $($ bar $)$ & 98 & 150 & 275 & 400 & 452 \\
$\mathbf{Z 3}$ & Co-solvent $(\%$ ethanol) & 5 & 7 & 11 & 15 & 17 \\
\hline
\end{tabular}

The obtained results were statistically processed using Statgraphics Centurion software XVI provided by Statpoint Technologies (Warrenton, VA, USA). Four different statistical parameters were used to evaluate the model fitting: coefficient of determination $\left(R^{2}\right)$, coefficient of variation $(C V)$, lack-of-fit test and model value [18].

Responses were fitted to the second-order polynomial model summarized in Equation (2):

$$
Y=\beta_{0}+\sum_{i=1}^{n} \beta_{i} Z_{i}+\sum_{i=1}^{n} \beta_{i i} Z_{i}^{2}+\sum_{i=1}^{n} \sum_{j=i+1}^{n} \beta_{i j} Z_{i} Z_{j}
$$

where $n$ is the number of variables; $\beta_{0}$ is a constant that fixes the response at the central point of the experiments; and $\beta_{i}, \beta_{i i}$ and $\beta_{i j}$ are the coefficients of the linear, quadratic and interaction parameters, respectively. The parameters $Z_{i}$ and $Z_{j}$ represent the values of independent variables, and, finally, $Y$ is the value of each response.

ANOVA tests were performed to evaluate the statistical significance of each independent factor ( $p$-values).

\subsection{Identification of Polar Profile of SFE Lemon Verbena Extracts by HPLC-ESI-TOF-MS}

Dried extracts were reconstituted using absolute ethanol until a concentration at $2500 \mu \mathrm{g} / \mathrm{mL}$ and filtered through a $0.2 \mu \mathrm{m}$ filter before analysis. An RRLC 1200 system was used to analyze the extracts (Agilent Technologies, Palo Alto, CA, USA). This analytical platform was equipped with a vacuum degasser, an automated sampler, a binary solvent delivery system and a UV-Vis detector. The RRLC system was coupled to a Bruker micrOTOF mass spectrometer (Bruker Daltonik, Bremen, Germany) using an electrospray interface (ESI) (model G1607 from Agilent Technologies, Palo Alto, CA, USA).

Phytochemical separation was accomplished using a $150 \mathrm{~mm} \times 4.6 \mathrm{~mm}$ id, $1.8 \mu \mathrm{m}$ particle diameter Zorbax Eclipse Plus C18 column (Agilent Technologies, Palo Alto, CA, USA). The eluents were water:acetonitrile $90: 10(\mathrm{v} / \mathrm{v})$ with $0.1 \%$ formic acid (eluent $\mathrm{A})$ and acetonitrile (eluent B). The injection volume was $10 \mu \mathrm{L}$, and the chromatographic separation was carried out according to a multistep gradient [17] in a total run time of $35 \mathrm{~min}$ at room temperature. The flow rate was $0.5 \mathrm{~mL} / \mathrm{min}$.

The effluent from the HPLC system was introduced into the mass spectrometer after reducing the flow rate with a "T"-type splitter, achieving a flow rate of less than $0.2 \mathrm{~mL} / \mathrm{min}$ and ensuring correct ionization by ESI. All MS assays were developed in negative ion mode and considering a mass range from 50 to $1000 \mathrm{~m} / \mathrm{z}$. The transfer and source parameters (capillary voltage, drying gas temperature, drying gas flow and nebulizing pressure) were set according to the literature [18]. It is necessary to remark that each analysis was externally calibrated at the beginning of each MS experiment with a sodium formate cluster injected by a 74900-00-05 Cole Palmer syringe pump (Vernon Hills, IL, USA). Moreover, mass spectra provided by MS equipment were calibrated before phytochemical characterization. This identification was accomplished with the use of Data Analysis 4.0 software (Bruker Daltonics, Billerica, MA, USA), whose sophisticated CHNO algorithm supported a good identification.

Four commercial standards (loganic acid, quercetin, verbascoside and kaempferol 3-glucoside) were used to quantify phenolics in samples. Calibration curves were performed with eleven points 
at different concentrations (from 0.5 to $150 \mu \mathrm{g} / \mathrm{mL}$ ), and apigenin $(25 \mu \mathrm{g} / \mathrm{mL}$ ) was used as internal standard. The linearity of all calibration curves was above 0.99 . Quantitation of phytochemicals was calculated by plotting the standard concentration as a function of the peak area (standard area/ internal standard area) and interpolating in the corresponding calibration curve. Total phytochemical family and total phenolic content in leaf extracts were tentatively calculated as the sum of the individual compound concentrations.

\section{Results}

\subsection{Identification and Quantitation of Phytochemical Profile of Supercritical Extracts of Lemon Verbena by LC/MS}

HPLC-ESI-TOF-MS analyses of SFE extracts were carried out to determine the potential application of SFE to recover phytochemicals from lemon verbena leaves. Figure 1 shows a representative base peak chromatogram (BPC) of SFE extracts. The numeration of the peaks was done according to their elution order (as compiled in Table 2). Furthermore, the calculated $\mathrm{m} / \mathrm{z}$, experimental $\mathrm{m} / \mathrm{z}$, molecular formula (M-H), mass error (ppm), isotopic pattern (mSigma) and proposed compound are also displayed.

The phenolic fraction consists of a heterogeneous mixture of compounds, which in most cases are not commercially available. Therefore, compounds which had no available commercial standards were tentatively quantitated using standards with similar structures. Phenylpropanoids were quantified using the verbascoside calibration curve. The loganic acid calibration curve was used to quantify iridoid glycosides, whereas flavonoids were quantified using the quercetin curve. Figure 2 shows the total polar content in SFE extracts for each chemical group calculated as a sum of the individual compound concentrations. The individual concentration of each compound is shown in Table S1.

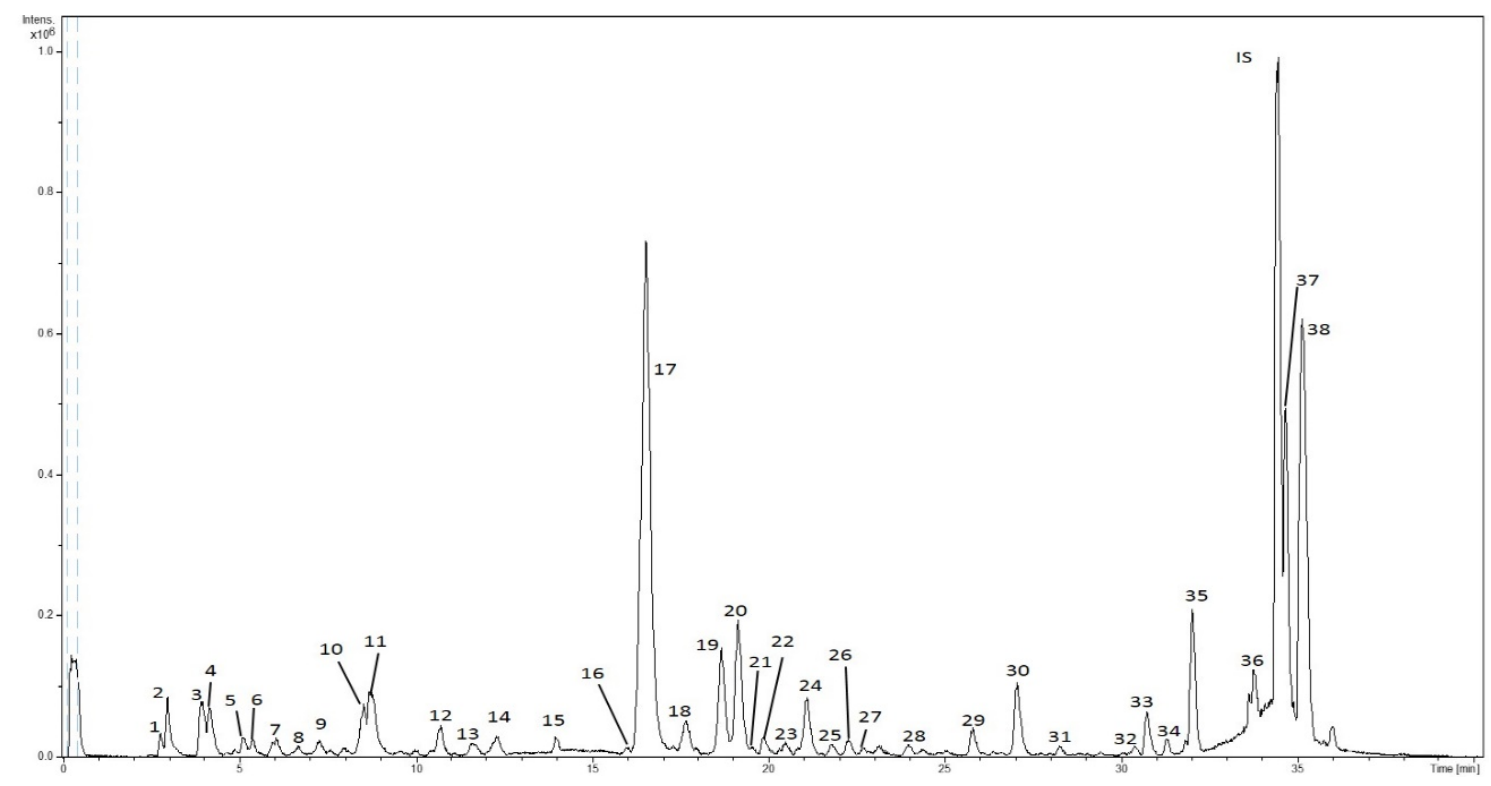

Figure 1. BPC of a supercritical extract of lemon verbena. 
Table 2. Polar composition of supercritical extracts of lemon verbena.

\begin{tabular}{|c|c|c|c|c|c|c|c|}
\hline Peak & $\begin{array}{c}\mathrm{RT} \\
(\mathrm{min})\end{array}$ & $\begin{array}{l}\text { Proposed } \\
\text { Compound }\end{array}$ & $m / z$ & $m / z \operatorname{Exp}$ & $\begin{array}{c}\text { Molecular } \\
\text { Formula }\end{array}$ & $\begin{array}{l}\text { Error } \\
(\mathrm{ppm})\end{array}$ & mSigma \\
\hline \multicolumn{8}{|c|}{ Iridoid glycosides } \\
\hline 2 & 3.0 & Shanzhiside & 391.1224 & 391.1246 & $\mathrm{C}_{16} \mathrm{H}_{23} \mathrm{O}_{11}$ & 5.6 & 27.2 \\
\hline 3 & 4.0 & Gardoside & 373.1142 & 373.1140 & $\mathrm{C}_{16} \mathrm{H}_{21} \mathrm{O}_{10}$ & -0.6 & 57.9 \\
\hline 7 & 6.0 & Theveside & 389.1097 & 389.1089 & $\mathrm{C}_{16} \mathrm{H}_{21} \mathrm{O}_{11}$ & -2.0 & 13.3 \\
\hline 9 & 7.3 & Myxopyroside & 449.1286 & 449.1301 & $\mathrm{C}_{18} \mathrm{H}_{25} \mathrm{O}_{13}$ & 3.3 & 9.4 \\
\hline 16 & 16.0 & Lamiidoside & 567.1719 & 567.1687 & $\mathrm{C}_{26} \mathrm{H}_{31} \mathrm{O}_{14}$ & 5.7 & 11.4 \\
\hline 21 & 19.6 & Hydroxy-campsiside & 521.1628 & 521.1664 & $\mathrm{C}_{25} \mathrm{H}_{29} \mathrm{O}_{12}$ & 7.0 & 44.2 \\
\hline 22 & 19.9 & Lippianoside B & 549.1608 & 549.1614 & $\mathrm{C}_{26} \mathrm{H}_{29} \mathrm{O}_{13}$ & 1.0 & 16.4 \\
\hline 23 & 20.5 & Durantoside I & 551.1769 & 551.1770 & $\mathrm{C}_{26} \mathrm{H}_{31} \mathrm{O}_{13}$ & 1.0 & 4.5 \\
\hline 34 & 31.2 & Manuleoside $\mathrm{H}$ & 569.2287 & 569.2240 & $\mathrm{C}_{27} \mathrm{H}_{37} \mathrm{O}_{13}$ & 6.1 & 9.9 \\
\hline \multicolumn{8}{|c|}{ Phenylpropanoids/phenylethanoids } \\
\hline 4 & 4.2 & Verbasoside & 461.1676 & 461.1664 & $\mathrm{C}_{20} \mathrm{H}_{29} \mathrm{O}_{12}$ & 3.9 & 7.3 \\
\hline 17 & 16.5 & Verbascoside & 623.2039 & 623.1981 & $\mathrm{C}_{29} \mathrm{H}_{35} \mathrm{O}_{15}$ & -1.6 & 2.9 \\
\hline 18 & 17.7 & $\begin{array}{c}\text { Lariciresinol } \\
\text { glucopyranoside }\end{array}$ & 521.2031 & 521.2028 & $\mathrm{C}_{26} \mathrm{H}_{33} \mathrm{O}_{11}$ & 4.4 & 28.8 \\
\hline 19 & 18.7 & Isoverbascoside & 623.1984 & 623.1981 & $\mathrm{C}_{29} \mathrm{H}_{35} \mathrm{O}_{15}$ & -0.5 & 12.2 \\
\hline 20 & 19.1 & Forsythoside A & 623.1990 & 623.1981 & $\mathrm{C}_{29} \mathrm{H}_{35} \mathrm{O}_{15}$ & -1.3 & 3.1 \\
\hline 24 & 21.1 & $\begin{array}{l}\text { Leucoseptoside A or } \\
\text { isomer }\end{array}$ & 637.2132 & 637.2138 & $\mathrm{C}_{30} \mathrm{H}_{37} \mathrm{O}_{15}$ & 1.3 & 5.7 \\
\hline 27 & 22.6 & $\begin{array}{l}\text { Leucoseptoside A or } \\
\text { isomer }\end{array}$ & 637.2138 & 637.2158 & $\mathrm{C}_{30} \mathrm{H}_{37} \mathrm{O}_{15}$ & -3.2 & 12.8 \\
\hline 30 & 27.0 & $\begin{array}{l}\text { Martynoside or } \\
\text { isomer }\end{array}$ & 651.2327 & 651.2294 & $\mathrm{C}_{31} \mathrm{H}_{39} \mathrm{O}_{15}$ & 0.6 & 16.1 \\
\hline 31 & 28.3 & $\begin{array}{l}\text { Martynoside or } \\
\text { isomer }\end{array}$ & 651.2327 & 651.2307 & $\mathrm{C}_{31} \mathrm{H}_{39} \mathrm{O}_{15}$ & -2.0 & 19.3 \\
\hline 33 & 30.7 & Osmanthisude B & $\begin{array}{l}591.2135 \\
\text { Flavonoids }\end{array}$ & 591.2083 & $\mathrm{C}_{29} \mathrm{H}_{35} \mathrm{O}_{13}$ & -8.8 & 17.3 \\
\hline 35 & 32.0 & Methyl-quercetin & 315.0540 & 315.0510 & $\mathrm{C}_{16} \mathrm{H}_{11} \mathrm{O}_{7}$ & -4.1 & 11.9 \\
\hline 37 & 34.6 & Dimethyl-kaempferol & 299.0539 & 299.0561 & $\mathrm{C}_{16} \mathrm{H}_{11} \mathrm{O}_{6}$ & 7.5 & 3.8 \\
\hline \multicolumn{8}{|c|}{ Oxylipins } \\
\hline 10 & 8.5 & $\begin{array}{l}\text { Tuberonic acid } \\
\text { glucoside }\end{array}$ & 387.1663 & 387.1661 & $\mathrm{C}_{18} \mathrm{H}_{27} \mathrm{O}_{9}$ & -0.7 & 4.5 \\
\hline 14 & 12.3 & Tuberonic acid & $\begin{array}{l}225.1143 \\
\text { Sugars }\end{array}$ & 225.1132 & $\mathrm{C}_{12} \mathrm{H}_{17} \mathrm{O}_{4}$ & 4.7 & 31.8 \\
\hline 1 & 2.8 & Disaccharide & & 341.1089 & $\mathrm{C}_{12} \mathrm{H}_{21} \mathrm{O}_{11}$ & 0.1 & 29.3 \\
\hline \multicolumn{8}{|c|}{ Other Compounds } \\
\hline 5 & 5.1 & or isomer & 203.0916 & 203.0925 & $\mathrm{C}_{9} \mathrm{H}_{15} \mathrm{O}_{5}$ & 4.2 & 3.8 \\
\hline 6 & 5.4 & $\begin{array}{c}\text { Dihydroharpagenin } \\
\text { or isomer }\end{array}$ & 203.0924 & 203.0925 & $\mathrm{C}_{9} \mathrm{H}_{15} \mathrm{O}_{5}$ & 0.4 & 15.7 \\
\hline 11 & 8.7 & $\begin{array}{l}\text { Hydroxy-epoxy-ionol } \\
\text { glucopyranoside }\end{array}$ & 387.1943 & 387.1966 & $\mathrm{C}_{19} \mathrm{H}_{31} \mathrm{O}_{8}$ & 9.4 & 7.3 \\
\hline \multicolumn{7}{|c|}{ Unknown } & 14.2 \\
\hline 8 & 6.7 & UK1 & 201.1123 & 201.1132 & $\mathrm{C}_{10} \mathrm{H}_{17} \mathrm{O}_{4}$ & 4.4 & 10.5 \\
\hline 12 & 10.7 & UK2 & 435.2181 & 435.2236 & $\mathrm{C}_{27} \mathrm{H}_{31} \mathrm{O}_{5}$ & -0.9 & 49.8 \\
\hline 13 & 11.6 & UK2 derivative & 433.2070 & 433.2079 & $\mathrm{C}_{27} \mathrm{H}_{29} \mathrm{O}_{5}$ & -2.6 & 55.3 \\
\hline 15 & 14.0 & UK3 & 201.1114 & 201.1132 & $\mathrm{C}_{10} \mathrm{H}_{17} \mathrm{O}_{4}$ & 5.5 & 18.9 \\
\hline 25 & 21.8 & UK4 & 417.2105 & 417.2130 & $\mathrm{C}_{20} \mathrm{H}_{33} \mathrm{O}_{9}$ & 5.6 & 8.4 \\
\hline 26 & 22.2 & UK5 & 187.0973 & 187.0976 & $\mathrm{C}_{9} \mathrm{H}_{15} \mathrm{O}_{4}$ & 5.7 & 10.1 \\
\hline 28 & 23.9 & UK6 & 183.1027 & 183.1034 & $\mathrm{C}_{10} \mathrm{H}_{15} \mathrm{O}_{3}$ & -4.1 & 14.6 \\
\hline 32 & 30.3 & UK7 & 375.2049 & 375.2024 & $\mathrm{C}_{18} \mathrm{H}_{31} \mathrm{O}_{8}$ & 0.4 & 14.0 \\
\hline 36 & 33.7 & Uk8 & 327.2202 & 327.2177 & $\mathrm{C}_{18} \mathrm{H}_{31} \mathrm{O}_{5}$ & 1.1 & 0.3 \\
\hline
\end{tabular}



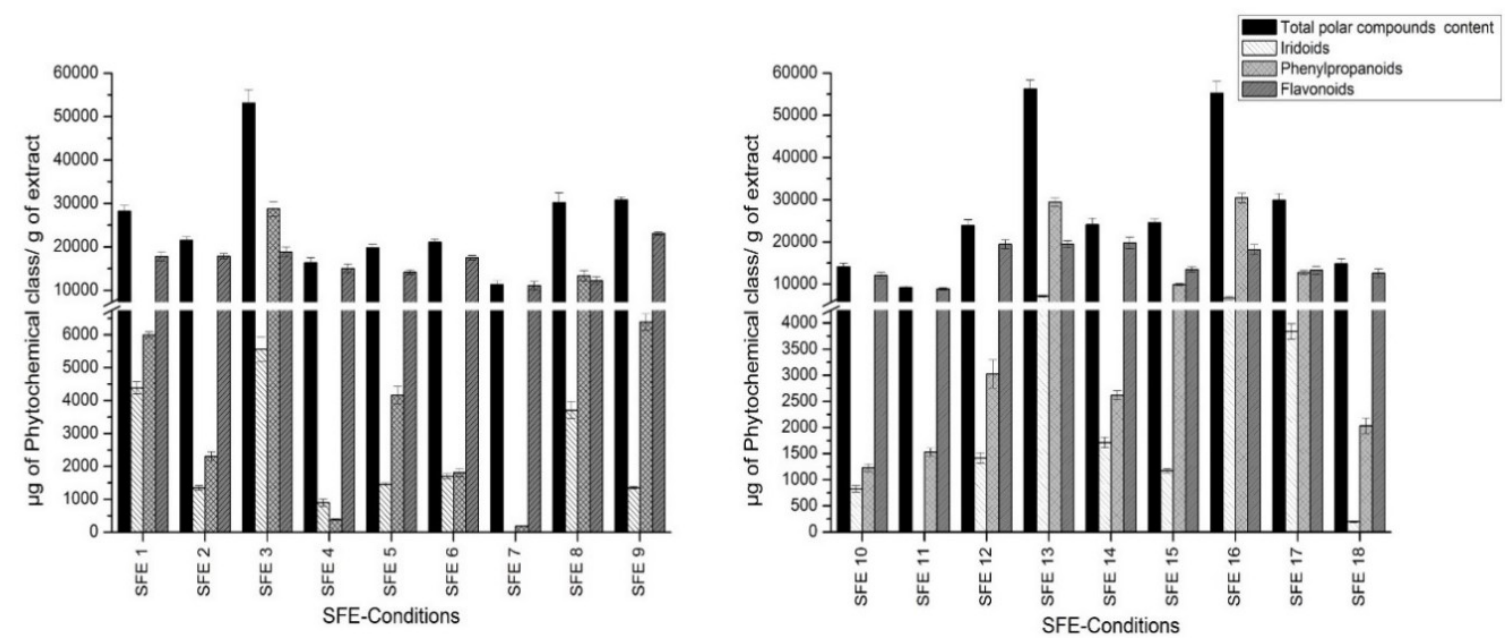

Figure 2. Quantitation of total polar content of obtained extracts.

A total of 38 compounds were detected in SFE extracts with the HPLC-ESI-TOF method. Of these compounds, 29 were identified by comparison of mass spectra and the available literature, and they were classified into six different groups corresponding to their chemical structures.

After examination of mass data provided by the analytical platform, a total of nine iridoid glycosides were found. According to their elution order, peaks 2 (shanzhiside), 3 (gardoside) and 7 (theveside) were previously identified in lemon verbena [14,19]. In addition, peak 9 was identified as myxopyroside, which was previously characterized in lemon verbena [17]. Moreover, compound 21 was identified as hydroxyl-campsiside, which was also detected in vegetable sources from the order Lamiales [20]. Compound 22 was tentatively identified as lippianoside B, which has also been found in Aloysa triphylla [21]. Compounds 23 and 34 were characterized as durantoside I and manuleoside, respectively [17]. Finally, compound 16, which displayed a retention time of $16.0 \mathrm{~min}$ and a molecular formula of $\mathrm{C}_{26} \mathrm{H}_{32} \mathrm{O}_{14}$, was identified as lamiidoside. This compound was tentatively characterized for the first time in lemon verbena, since it was previously identified in Duranta erecta (Lamiales) [22].

Considering the results of the iridoid quantification shown in Figure 2, the highest iridoid retrieval was provided by SFE condition $13\left(40{ }^{\circ} \mathrm{C}, 400 \mathrm{bar}, 15 \%\right.$ co-solvent): $7172 \mu \mathrm{g}$ of iridoids/g of extract. Condition $7\left(60^{\circ} \mathrm{C}, 150 \mathrm{bar}, 7 \%\right.$ co-solvent) was shown to be the worst in terms of recovering this chemical group. It is necessary to remark that gardoside was the most representative iridoid, and its concentration ranged from 3057 (SFE 3; $50{ }^{\circ} \mathrm{C}, 275 \mathrm{bar}, 17 \%$ co-solvent) to $3136 \mu \mathrm{g}$ of gardoside/g of extract (SFE 13). These results differ from the other outcomes reported for lemon verbena extractions, where theveside was the most abundant iridoid [17]. The rest of the iridoid glycosides showed greater variation depending on the condition applied.

In addition, the HPLC-ESI-TOF-MS platform provided information for ten phenylpropanoids. Indeed, the majority of the characterized phenolic compounds belonged to this chemical group. Compound 4 was characterized as verbasoside. Compounds 17, 19 and 20 displayed molecular formula allowing them to be identified according to a previously reported elution order as verbascoside, isoverbascoside and forsythoside A, respectively [23]. Verbascoside and its isomers are considered as the most representative phenylpropanoids in lemon verbena [17]. Moreover, compound 18 was also detected in the Lippia genus and was identified as lariciresinol glucopyranoside [21]. Compound 33 was determined to be osmanthisude B. In addition, two compounds were also detected that showed the same molecular formula $\left(\mathrm{C}_{30} \mathrm{H}_{38} \mathrm{O}_{15}\right)$ : leucoseptoside $\mathrm{A}$ (peak 24) and an isomer (peak 27). They were found in Eremophila maculata, a plant belonging to the order Lamiales [24]. Peaks 30 and 31 had the same $\mathrm{m} / \mathrm{z}$ and similar retention times, and they were characterized as martynoside and its isomer, respectively [17]. 
As far as phenylpropanoid quantification is concerned, the range of retrieval was from 184 (SFE 7; $60{ }^{\circ} \mathrm{C}, 150 \mathrm{bar}, 7 \%$ co-solvent) to $30,448 \mu \mathrm{g}$ of phenylpropanoids/g of extract (SFE $16 ; 60{ }^{\circ} \mathrm{C}, 400 \mathrm{bar}, 15 \%$ co-solvent). Verbascoside was the most abundant compound, showing greater amounts in extracts SFE 3,13 and 16 and reaching an amount of $21,984 \mu \mathrm{g}$ of verbascoside/g of extract.

Overall, the applied method enabled the separation and identification of three different flavonoids, all of them eluted at the end of the analytical run. The first eluted compound was methyl-quercetin (peak 35). Furthermore, peak 37 was tentatively identified as dimethyl-kaempferol. The last flavonoid eluted from the column was dimethyl-quercetin (peak 38). All of them were previously described in Lippia [17]. These compounds were found in great amounts throughout the experiment, reaching values from 8921 to $23,113 \mu \mathrm{g}$ of flavonoids/g of extract. In this sense, dimethyl quercetin was the most abundant flavonoid in SFE $9\left(36^{\circ} \mathrm{C}, 275 \mathrm{bar}, 11 \%\right.$ co-solvent $)$, reaching the level of $15,622 \mu \mathrm{g}$ of dimethyl quercetin/g of extract. The rest of flavonoids also yielded with positive results.

Regarding other chemical compounds, only two compounds were found within the oxylipin group. Thus, compound 10 yielded a deprotonated molecular formula of $\mathrm{C}_{18} \mathrm{H}_{27} \mathrm{O}_{9}$ and was characterized as tuberonic acid glucoside according to the literature (Quirantes-Piné et al., 2013). Besides, peak 14 was characterized as its aglycone form, tuberonic acid.

Peak 1 gave an $\mathrm{m} / \mathrm{z}$ at 341.1089 and a deprotonated molecular formula of $\mathrm{C}_{12} \mathrm{H}_{21} \mathrm{O}_{11}$. This compound was previously detected in lemon verbena as a disaccharide [25]. Peaks 5 and 6 presented the same $\mathrm{m} / \mathrm{z}$ at 203.0925, and they were identified as dihydroharpagenin isomers. This association was made on the basis that these compounds were previously detected in plants from the order Lamiales [26]. Furthermore, a novel compound was tentatively identified in lemon verbena and related to peak 11. The MS spectra generated a molecular formula $\left(\mathrm{C}_{19} \mathrm{H}_{31} \mathrm{O}_{8}\right)$ enabling its characterization as hydroxyl-epoxy-ionol-glucopyranoside. This compound was previously found in Isodon japonicus (Lamiaceae family) [27]. Finally, a primeverin derivative was found and associated to peak 29. It was characterized as octen-primeveroside.

It is necessary to remark that this extraction technique provided a lower variety of compounds from lemon verbena compared to previous reports which applied different extraction methods to retrieve bioactive compounds from lemon verbena. Nevertheless, this extraction method allowed the recovery of up to six different compounds which could not be extracted from lemon verbena using other techniques. Moreover, extracts were obtained that had greater concentrations of methylated flavonoids than those from other extraction techniques performed on this botanical source $[17,18]$. Hence, SFE offered higher selectivity in the extraction of some compounds.

\subsection{Effect of Independent Variables on Extraction Yield and Bioactive Compound Recovery}

With the purpose of evaluating the effects of each factor (temperature, pressure and co-solvent percentage) on the response variables (yield and total polar compound contents), an RSM based on a $2^{3}$ CCD was developed. Table 3 compiles the influence of each factor, and Figure 3B,D includes the obtained Pareto plots for each response variable. These plots are tools that provide graphical information to understand the response variable behavior and the influence of each independent variable at a $95 \%$ confidence interval. 
Table 3. Equation coefficients and $p$-Value for the independent variables $\left(\beta_{0}\right.$, independent constant, $\beta_{1}$, Temperature; $\beta_{2}$, Pressure; $\beta_{3}$, Co-solvent).

\begin{tabular}{ccccc}
\hline \multirow{2}{*}{ Factors } & \multicolumn{2}{c}{ Total Polar Content } & \multicolumn{2}{c}{ Yield } \\
\cline { 2 - 5 } & Coefficient & $\boldsymbol{p}$-Value & Coefficient & $p$-Value \\
\hline$\beta_{0}$ & $174,734.000$ & & -3.910 & \\
$\beta_{1}$ & -4819.360 & 0.523 & -0.050 & ${ }^{*} 0.023$ \\
$\beta_{2}$ & -141.311 & ${ }^{*} 0.012$ & 0.022 & ${ }^{*} 0.030$ \\
$\beta_{3}$ & -7406.600 & ${ }^{*} 0.003$ & 0.863 & 0.133 \\
$\beta_{1} \cdot \beta_{1}$ & 44.199 & 0.075 & 0.002 & 0.091 \\
$\beta_{2} \cdot \beta_{2}$ & -0.033 & 0.772 & -0.000 & 0.067 \\
$\beta_{3} \cdot \beta_{3}$ & 301.068 & 0.062 & -0.016 & ${ }^{*} 0.032$ \\
$\beta_{1} \cdot \beta_{2}$ & 1.570 & 0.320 & -0.000 & 0.123 \\
$\beta_{1} \cdot \beta_{3}$ & 5.891 & 0.895 & -0.006 & ${ }^{*} 0.045$ \\
$\beta_{2} \cdot \beta_{3}$ & 12.713 & ${ }^{*} 0.031$ & -0.016 & ${ }^{*} 0.017$ \\
\hline
\end{tabular}

* Significant coefficients $(p<0.050)$.

A)
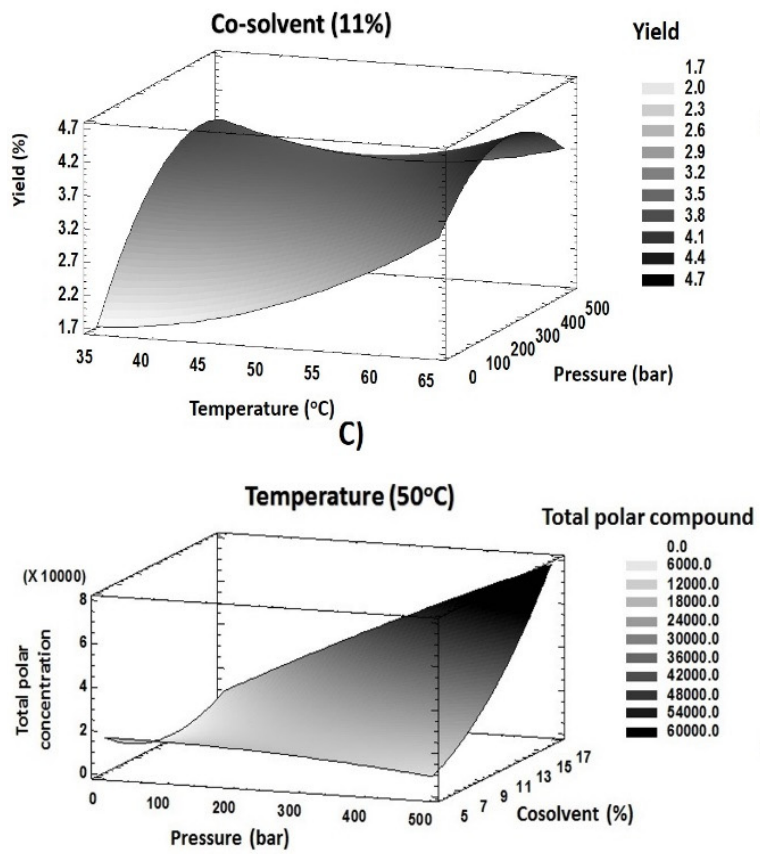

B) Extraction yield Pareto chart of standarized effects

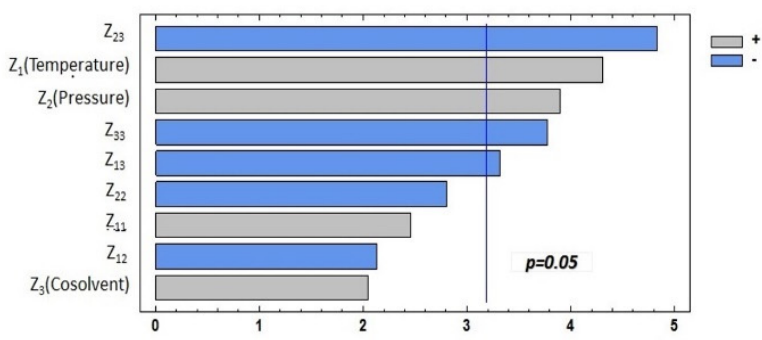

D)

Total polar compounds Pareto chart of standarized effects

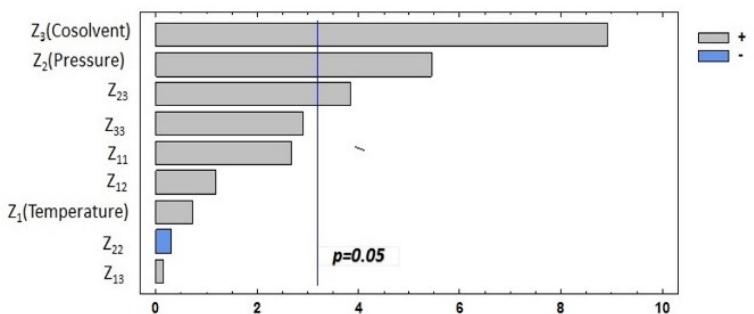

Figure 3. Response surface methodology $(\operatorname{RSM})(\mathbf{A}, \mathbf{C})$ and Pareto $(\mathbf{B}, \mathbf{D})$ plots of response variables evaluated.

Temperature is a determining factor since higher values generate variation in supercritical fluid density and consequently in its penetration capability. Furthermore, the solubility of specific compounds is increased when temperature is raised [28]. Both scenarios enabled the retrieval of compounds from raw material. Therefore, at constant pressure, an increase of temperature produces a decrease of supercritical fluid density and consequently improves the compounds' solubility [29].

Concerning extraction yield, temperature showed a significant positive effect on this response (Figure 3B). These results indicated that a high temperature caused a rupture of plant cells and enabled all components in them (both desirable and nondesirable compounds) to be released. Moreover, the low density of solvents at a high temperature allowed better wetting of leaves and therefore enabled the transfer of heat into the sample. All of this contributed to a great retrieval of a wide variety of compounds, increasing the amount of extracts recovered after supercritical procedures. 
Although high temperatures may degrade some thermosensitive compounds [30,31], the results in Figure 3D and Table 3 show that temperature had a positive influence on the recovery of polar compounds. These results may be due to the different structures of compounds and the raw material. However, this factor did not present any significant values. According to other studies, the decrease of density caused by high temperatures could enable the penetration of solvents into the matrix, improving the solubility of polar compounds into the solvent mix [11,29].

On the other hand, extraction yield and pressure were positively correlated (Figure 3B). The results revealed that higher pressures produced an improvement of extraction yield according to $\mathrm{CO}_{2}$ and co-solvent densities, which were increased at higher pressures, resulting in greater solvation power and, consequently, an increased recovery of compound contents in the sample. The sum of all components extracted from the plant generated an increase in the quantity of attained extract. Pressure also showed a positive effect on the total polar compound content. In previous studies, it has been reported that greater recoveries of phenolic compounds from plants were achieved at high pressure values [32]. This could be related to the effect of great pressures on solvents, such as $\mathrm{CO}_{2}$ and ethanol. Indeed, high pressure values generate an increase in solvent and co-solvent densities; consequently, this fact modifies solute solubility [33].

The percentage of co-solvent added as modifier causes a polarity adjustment that is necessary to achieve great recoveries of phenolics due to their hydrophilic character. As far as extraction yield is concerned, co-solvent exerted a significant negative influence combined with both pressure and temperature. According to previous reports, high concentrations of ethanol added into the solvent mix may hinder the retrieval of components from matrix. This effect could be related to the reduction of the extraction mixture homogeneity [29]. Nevertheless, ethanol was needed to improve the solubility of polar compounds [28]. Moreover, the addition of an organic co-solvent such as ethanol improves the solvating power of supercritical fluids [34]. Therefore, an increase of co-solvent concentration could provide a greater retrieval of polar compounds. Indeed, this independent factor had the most influential positive effect on polar compound content. Furthermore, the interaction between this factor and pressure also had significant effects. These outcomes could indicate that co-solvent addition reduced the supercritical fluid polarity, increasing the solubility of polar compounds. Meanwhile, pressure contributed in improving the solubility of phytochemicals.

\subsection{Evaluation of Model Fitting Parameters}

The evaluation of the influence of each factor on the response variables enabled the establishment of the optimal conditions and the maximization of extraction yield and the phytochemical recovery from lemon verbena. This goal was achieved using several fitting parameters which were assessed in order to determine the model adequacy. ANOVA test results are shown in Table 4. Both responses displayed a good homogeneity of the experimental data, as revealed their CV. In this sense, total polar compound content presented $10.42 \%$, whereas extraction yield presented $2.57 \%$. Moreover, an accurate prediction of response behavior was reached with the proposed experimental model $\left(R^{2}\right)$ (Table 5). Indeed, $90 \%$ of the obtained results could be predicted with this experimental model. Moreover, to evaluate the model adequacy, two parameters were also evaluated. Firstly, lack-of-fit revealed an acceptable adequacy of the proposed model, since both responses revealed nonsignificant values $(p>0.05)$. Lastly, model adequacy showed a great adjustment to total polar compound content response. Unfortunately, extraction yield did not have a good fitting, since the $p$-value was nonsignificant. The data were statistically evaluated by implementing response surface models (Figure $3 \mathrm{~A}, \mathrm{C}$ ) which enabled the determination of the region of extraction factors that would maximize the variable responses. Moreover, the coefficients displayed in Table 3 and the experimental results shown in Table 5 support these optimal conditions. 
Table 4. Fitting parameters for the full model.

\begin{tabular}{|c|c|c|c|c|c|c|c|c|c|c|}
\hline & \multicolumn{5}{|c|}{ Total Polar } & \multicolumn{5}{|c|}{ Yield } \\
\hline & Sum of Squares & $\begin{array}{l}\text { Degrees of } \\
\text { Freedom }\end{array}$ & Mean Squares & Fisher-Ratio & $p$-Value & $\begin{array}{l}\text { Sum of } \\
\text { Squares }\end{array}$ & $\begin{array}{l}\text { Degrees of } \\
\text { Freedom }\end{array}$ & Mean Squares & Fisher Ratio & $p$-Value \\
\hline Model & $2.393 \times 10^{9}$ & 3 & $7.976 \times 10^{8}$ & 10.014 & $<0.001 *$ & 1.468 & 3 & 0.489 & 2.187 & 0.135 \\
\hline Residual & $1.115 \times 10^{9}$ & 14 & $7.965 \times 10^{7}$ & & & 3.133 & 14 & 0.224 & & \\
\hline Lack-of-fit & $3.510 \times 10^{8}$ & 5 & $7.020 \times 10^{7}$ & 3.220 & 0.182 & 0.426 & 5 & 0.0851 & 2.200 & 0.274 \\
\hline Pure error & $6.540 \times 10^{7}$ & 3 & $2.180 \times 10^{7}$ & & & 0.116 & 3 & 0.0387 & & \\
\hline Total (corr.) & $3.510 \times 10^{9}$ & 17 & & & & 4.601 & 17 & & & \\
\hline $\mathbf{R}^{2}$ & 0.881 & & & & & 0.882 & & & & \\
\hline $\mathrm{CV}$ & 10.42 & & & & & 2.57 & & & & \\
\hline
\end{tabular}


Table 5. Experimental and predicted data for the response variables obtained from the CCD.

\begin{tabular}{cccccccc}
\hline \multirow{2}{*}{ Experimental Point } & $Z_{\mathbf{1}}$ & $Z_{\mathbf{2}}$ & $Z_{\mathbf{3}}$ & \multicolumn{2}{c}{ Extraction Yield } & \multicolumn{2}{c}{ Total Content * } \\
\cline { 5 - 8 } & & & & Predicted & Observed & Predicted & Observed \\
\hline 1 & 60 & 150 & 15 & 3.717 & 3.692 & 29,319 & $28,213 \pm 1381$ \\
2 & 50 & 275 & 11 & 3.612 & 3.582 & 20,766 & $21,521 \pm 821$ \\
3 & 50 & 275 & 17 & 3.251 & 3.207 & 47,414 & $53,152 \pm 3111$ \\
4 & 50 & 98 & 11 & 2.908 & 2.945 & 10,401 & $16,348 \pm 1138$ \\
5 & 40 & 150 & 15 & 3.393 & 3.448 & 27,376 & $19,799 \pm 832$ \\
6 & 40 & 150 & 7 & 2.028 & 2.159 & 16,029 & $21,069 \pm 700$ \\
7 & 60 & 150 & 7 & 3.275 & 3.027 & 17,971 & $11,279 \pm 988$ \\
8 & 60 & 400 & 7 & 4.093 & 3.978 & 19,917 & $30,183 \pm 2312$ \\
9 & 36 & 275 & 11 & 3.607 & 3.343 & 28,232 & $30,830 \pm 639$ \\
10 & 50 & 275 & 11 & 3.612 & 3.521 & 20,766 & $14,125 \pm 848$ \\
11 & 50 & 275 & 5.3 & 2.922 & 3.086 & 13,387 & $9182 \pm 352$ \\
12 & 50 & 275 & 11 & 3.612 & 3.847 & 20,766 & $23,895 \pm 1384$ \\
13 & 40 & 400 & 15 & 3.461 & 3.648 & 54,748 & $56,279 \pm 2096$ \\
14 & 50 & 275 & 11 & 3.612 & 3.377 & 20,766 & $24,085 \pm 1572$ \\
15 & 50 & 452 & 11 & 3.535 & 3.618 & 31,131 & $24,626 \pm 828$ \\
16 & 60 & 400 & 15 & 3.193 & 3.002 & 56,691 & $55,282 \pm 2760$ \\
17 & 64 & 275 & 11 & 4.299 & 4.683 & 30,980 & $29,915 \pm 1552$ \\
18 & 40 & 400 & 7 & 3.439 & 3.404 & 17,974 & $14,861 \pm 1163$ \\
\hline
\end{tabular}

* Concentrations are expressed as $\mu \mathrm{g}$ of analyte/g dried extract; $Z_{1}$ represents temperature $\left({ }^{\circ} \mathrm{C}\right), Z_{2}$ represents pressure (bar) and $Z_{3}$ represents co-solvent percentage.

\subsubsection{Extraction Yield Optimization}

Regarding extraction yield, the obtained values ranged from 2.028 to $4.683 \%$. Although SFE may provide a selective extraction of bioactive compounds, the efficiency of the process was much lower than other techniques such as pressurized liquid extraction and microwave-assisted extraction $[17,18]$ applied on lemon verbena. However, these results were similar to those obtained by SFE procedure performed on Hibiscus sabdariffa or Lavandula angustifolia [31,35] but better than those of the SFE of Castanea sativa shells [36]. Considering Table 5, the best condition to attain greater yields was SFE 17 ( $64{ }^{\circ} \mathrm{C}, 275$ bar, $11 \%$ co-solvent). Equation (3) summarizes a relationship between the extraction yield and significant independent variables:

$$
Y=-5.620+0.088 Z_{1}+0.009 Z_{2}-0.016 Z_{3}^{2}-0.006 Z_{1} Z_{3}-0.001 Z_{2} Z_{3}
$$

These results revealed that the linear effect of temperature contributed in a greater measure than the single effect of pressure. Concerning the interaction between factors and according to Figure $3 \mathrm{~B}$, the interaction between pressure and co-solvent contributed more than the interaction between temperature and co-solvent. Figure $3 \mathrm{~A}$ shows the extraction yield behavior according to the two most influential factors (temperature and pressure). In this plot, it can be seen that the maximum extraction yield was achieved when medium pressure and high temperature were applied. These results supported the establishment of optimum conditions at $64{ }^{\circ} \mathrm{C}, 379$ bar and $7 \%$ co-solvent. The model resulted in a predictable yield value of $4.928 \%$, which was higher than the experimental result obtained in condition 17 (4.299\%).

\subsubsection{Total Polar Compound Content Optimization}

Table 5 reports the total polar compound contents obtained at each experimental point. Overall, the values ranged from 9182 to $56,279 \mu \mathrm{g}$ of polar compound/g of dried extract. Conditions $13\left(40^{\circ} \mathrm{C}\right.$, 400 bar, $15 \%$ co-solvent), $16\left(60{ }^{\circ} \mathrm{C}, 400\right.$ bar, $15 \%$ co-solvent) and $3\left(50{ }^{\circ} \mathrm{C}, 275\right.$ bar, $17 \%$ co-solvent) enabled a great retrieval, upwards of 50,000 $\mu \mathrm{g}$ of polar compound/g of dried extract, whereas SFE 11 $\left(50{ }^{\circ} \mathrm{C}, 275 \mathrm{bar}, 5 \%\right.$ co-solvent) yielded the lowest polar compound recovery. 
After examining the results of the experimental design and analyzing the effect of each factor and its combinatory effects on the total polar compound content, this response variable was fitted in a simplified quadratic equation that includes only the significant factors (Equation (4)):

$$
Y=16174.300-81.211 Z_{2}-488.563 Z_{3}+12.713 Z_{2} Z_{3}
$$

As mentioned above, pressure and percentage of ethanol were the most influential factors on polar compound extraction. This behavior was similar to that previously reported by Espinosa-Pardo and Roselló-Soto $[11,36]$. According to the Figure 3D and this reduced model, the percentage of co-solvent was the main determinant in increasing the retrieval of compounds.

The good adjustment of this response enabled optimal conditions for maximizing this response to be discerned. In this sense, Figure $3 \mathrm{C}$ displays the total polar compound content. This plot shows the effect of pressure and co-solvent at constant temperature on the selected response variable and provides the optimal values at $57^{\circ} \mathrm{C}, 451 \mathrm{bar}$ and $17 \%$ co-solvent. Here, the pressure was the highest value that the supercritical fluid equipment allowed, whereas the percentage of ethanol cannot be higher because it would not assure the supercritical state of $\mathrm{CO}_{2}$ throughout the proposed conditions in the experimental design. The predicted result obtained after applying these optimum conditions was $73,982 \mu \mathrm{g}$ of polar compound/g of dried extract. This value was considerably greater than that obtained in SFE 13, which showed the highest polar compound recovery.

\section{Conclusions}

In this study, a new experimental design was created with the purpose of obtaining high-quality phenolic extracts to develop functional food. The dependent variables of total phenolic content and yield were successfully optimized. The fitting parameters of the proposed model indicated that the second-order polynomial model gave a mathematical explanation of the SFE procedures. Indeed, the proposed model allowed an accurate prediction of the studied response variables and enabled the effects of each factor during SFE processing to be discerned. In this sense, the percentage of co-solvent was the determinant in increasing the retrieval of compounds, whereas temperature was revealed to be an important parameter in increasing extraction yield. The individual action of pressure or its interaction with other factors enabled the maximization of each response. Particularly, flavonoids were recovered in higher concentrations, whereas iridoid glycoside retrieval was lower. Finally, verbascoside was the most recovered phenylpropanoid. These results, compared with previous reports, revealed that SFE allowed the extraction of six new compounds in lemon verbena and enabled higher recoveries of some compounds, such as methylated flavonoids, than those of other advanced extraction methods, enhancing the obtainment of enriched extracts in specific chemical groups. It should be considered that the use of the SFE process provided a more selective phytochemical extraction from lemon verbena, as well as the retrieval of new compounds. Therefore, the evaluation of the impact of the independent variables provides useful information for the industrial process scale-up of the extraction of lemon verbena functional ingredients.

Supplementary Materials: The following are available online at http://www.mdpi.com/2304-8158/9/7/931/s1, Table S1: Quantitation of individual compounds presents in L. citriodora supercritical extracts ( $\mu \mathrm{g}$ of analyte/g of dried extract). Value $=\mathrm{X} \pm \mathrm{SD}$.

Author Contributions: Conceptualization, J.L.-S.; data curation, F.-J.L.-J. and J.L.-S.; formal analysis, F.J.L.-J. and Á.F.-O.; funding acquisition, A.S.-C. and D.A.-R.; investigation, F.J.L.-J., M.d.l.L.C.-G. and J.L.-S.; methodology, F.J.L.-J. and J.L.-S.; project administration, A.S.-C. and D.A.-R.; resources, A.S.-C.; software, F.J.L.-J., M.d.1.L.C.-G. and Á.F.-O.; supervision, A.S.-C. and J.L.-S.; writing—original draft, F.J.L.-J.; writing—review \& editing, J.L.-S., M.d.l.L.C.-G. and Á.F.-O. All authors have read and agreed to the published version of the manuscript.

Funding: This research was funded by Ministry of Science, Innovation and Universities, grant number RTI2018-096724-B-C22. 
Acknowledgments: This work was funded by projects AGL2015-67995-C3-2-R (Spanish Ministry of Science and Innovation), P11-CTS-7625 (Andalusian Regional Government Council of Innovation and Science) and RTI2018-096724-B-C22 (Ministry of Science, Innovation and Universities). The author Leyva-Jimenez gratefully acknowledges the Spanish Ministry of Economy and Competitiveness (MINECO) for the FPI grant BES-2016-076618 given to develop this work. The authors are also grateful to the University of Granada for a "Contrato Puente" postdoctoral contract (AFO) and a "Perfeccionamiento de Doctores" postdoctoral contract (MdlLCG).

Conflicts of Interest: The authors declare no conflict of interest.

\section{References}

1. Barba, F.J.; Criado, M.N.; Belda-Galbis, C.M.; Esteve, M.J.; Rodrigo, D. Stevia rebaudiana Bertoni as a natural antioxidant/antimicrobial for high pressure processed fruit extract: Processing parameter optimization. Food Chem. 2014, 148, 261-267. [CrossRef]

2. Pimentel-Moral, S.; Borrás-Linares, I.; Lozano-Sánchez, J.; Arráez-Román, D.; Martínez-Férez, A.; Segura-Carretero, A. Microwave-assisted extraction for Hibiscus sabdariffa bioactive compounds. J. Pharm. Biomed. Anal. 2018, 156, 313-322. [CrossRef] [PubMed]

3. Ameer, K.; Shahbaz, H.M.; Kwon, J.H. Green Extraction Methods for Polyphenols from Plant Matrices and Their Byproducts: A Review. Compr. Rev. Food Sci. Food Saf. 2017, 16, 295-315. [CrossRef]

4. Roselló-Soto, E.; Koubaa, M.; Moubarik, A.; Lopes, R.P.; Saraiva, J.A.; Boussetta, N.; Grimi, N.; Barba, F.J. Emerging opportunities for the effective valorization of wastes and by-products generated during olive oil production process: Non-conventional methods for the recovery of high-added value compounds. Trends Food Sci. Technol. 2015, 45, 296-310. [CrossRef]

5. Kazan, A.; Koyu, H.; Turu, I.C.; Yesil-Celiktas, O. Supercritical fluid extraction of Prunus persica leaves and utilization possibilities as a source of phenolic compounds. J. Supercrit. Fluids 2014, 92, 55-59. [CrossRef]

6. Urbonaviciene, D.; Viskelis, $\mathrm{P}$. The cis -lycopene isomers composition in supercritical $\mathrm{CO}_{2}$ extracted tomato by-products. LWT Food Sci. Technol. 2017, 85, 517-523. [CrossRef]

7. Song, L.; Liu, P.; Yan, Y.; Huang, Y.; Bai, B.; Hou, X.; Zhang, L. Supercritical $\mathrm{CO}_{2}$ fluid extraction of flavonoid compounds from Xinjiang jujube (Ziziphus jujuba Mill.) leaves and associated biological activities and flavonoid compositions. Ind. Crops Prod. 2019, 139, 111508.

8. Bogolitsyn, K.; Krasikova, A.; Gusakova, M.; Ivakhnov, A.; Gravitis, J. Selective extraction of terpenoid compounds of Juniperus communis L.wood in the medium of a binary solvent (supercritical $\mathrm{CO}_{2}$ with modifier). Phytochem. Anal. 2019, 30, 609-616. [CrossRef]

9. Koubaa, M.; Rosello, E.; Jana, S.Z.; Rez, A.; Grimi, N.; Boussetta, N.; Barba, F.J. Current and New Insights in the Sustainable and Green Recovery of Nutritionally Valuable Compounds from Stevia rebaudiana Bertoni. J. Agric. Food Chem. 2015, 63, 6835-6846. [CrossRef]

10. Tyśkiewicz, K.; Konkol, M.; Rój, E. The Application of Supercritical Fluid Extraction in Phenolic Compounds Isolation from Natural Plant Materials. Molecules 2018, 23, 2625. [CrossRef]

11. Espinosa-Pardo, F.A.; Nakajima, V.M.; Macedo, G.A.; Macedo, J.A.; Martínez, J. Extraction of phenolic compounds from dry and fermented orange pomace using supercritical $\mathrm{CO}_{2}$ and cosolvents. Food Bioprod. Process. 2017, 101, 1-10. [CrossRef]

12. Del Pilar Sánchez-Camargo, A.; Valdés, A.; Sullini, G.; García-Cañas, V.; Cifuentes, A.; Ibáñez, E.; Herrero, M. Two-step sequential supercritical fluid extracts from rosemary with enhanced anti-proliferative activity. J. Funct. Foods 2014, 11, 293-303. [CrossRef]

13. Da Porto, C.; Decorti, D.; Natolino, A. Water and ethanol as co-solvent in supercritical fluid extraction of proanthocyanidins from grape marc: A comparison and a proposal. J. Supercrit. Fluids 2014, 87, 1-8. [CrossRef]

14. De la Luz Cádiz-Gurrea, M.; Olivares-Vicente, M.; Herranz-López, M.; Román-Arráez, D.; Fernández-Arroyo, S.; Micol, V.; Segura-Carretero, A. Bioassay-guided purification of Lippia citriodora polyphenols with AMPK modulatory activity. J. Funct. Foods 2018, 46, 514-520. [CrossRef]

15. Diez-Echave, P.; Vezza, T.; Rodríguez-Nogales, A.; Hidalgo-Garcia, L.; Garrido-Mesa, J.; Ruiz-Malagon, A.; Molina-Tijeras, J.A.; Romero, M.; Robles-Vera, I.; Leyva-Jiménez, F.J.; et al. The Beneficial Effects of Lippia Citriodora Extract on Diet-Induced Obesity in Mice Are Associated with Modulation in the Gut Microbiota Composition. Mol. Nutr. Food Res. 2020, 2000005. [CrossRef] [PubMed] 
16. Herranz-López, M.; Barrajón-Catalán, E.; Segura-Carretero, A.; Menéndez, J.A.; Joven, J.; Micol, V. Lemon verbena (Lippia citriodora) polyphenols alleviate obesity-related disturbances in hypertrophic adipocytes through AMPK-dependent mechanisms. Phytomedicine 2015, 22, 605-614. [CrossRef] [PubMed]

17. Leyva-Jiménez, F.J.; Lozano-Sánchez, J.; Borrás-Linares, I.; Arráez-Román, D.; Segura-Carretero, A. Comparative study of conventional and pressurized liquid extraction for recovering bioactive compounds from Lippia citriodora leaves. Food Res. Int. 2018, 109, 213-222. [CrossRef]

18. Leyva-Jiménez, F.J.; Lozano-Sánchez, J.; Borrás-Linares, I.; Arráez-Román, D.; Segura-Carretero, A. Manufacturing design to improve the attainment of functional ingredients from Aloysia citriodora leaves by advanced microwave technology. J. Ind. Eng. Chem. 2019, 79, 52-61. [CrossRef]

19. Quirantes-Piné, R.; Arráez-Román, D.; Segura-Carretero, A.; Fernández-Gutiérrez, A. Characterization of phenolic and other polar compounds in a lemon verbena extract by capillary electrophoresis-electrospray ionization-mass spectrometry. J. Sep. Sci. 2010, 33, 2818-2827. [CrossRef]

20. Imakura, Y.; Kobayashi, S.; Kida, K.; Kido, M. Iridoid glucosides from Campsis chinensis. Phytochemistry 1984, 23, 2263-2269. [CrossRef]

21. Wang, T.; Zhang, Y.; Chen, Y.; Wang, S.; Dong, Y.; Wang, T.; Qu, L.; Li, N. Bioactive constituents from the aerial parts of Lippia triphylla. Molecules 2015, 20, 21946-21959.

22. Takeda, Y.; Morimoto, Y.; Matsumoto, T.; Ogimi, C.; Hirata, E.; Takushi, A.; Otsuka, H. Iridoid glucosides from the leaves and stems of Duranta erecta. Phytochemistry 1995, 39, 829-833. [CrossRef]

23. Quirantes-Piné, R.; Herranz-López, M.; Funes, L.; Borrás-Linares, I.; Micol, V.; Segura-Carretero, A.; Fernández-Gutiérrez, A. Phenylpropanoids and their metabolites are the major compounds responsible for blood-cell protection against oxidative stress after administration of Lippia citriodora in rats. Phytomedicine 2013, 20, 1112-1118. [CrossRef] [PubMed]

24. Youssef, F.S.; Ashour, M.L.; Ebada, S.S.; Sobeh, M.; El-Beshbishy, H.A.; Singab, A.N.; Wink, M. Antihyperglycaemic activity of the methanol extract from leaves of Eremophila maculata (Scrophulariaceae) in streptozotocin-induced diabetic rats. J. Pharm. Pharmacol. 2017, 69, 733-742. [CrossRef]

25. Yosioka, I.; Sugawara, T.; Yoshikawa, K.; Kitagawa, I. Soil Bacterial Hydrolysis leading to Genuine Aglycone. VII. On Monoterpenoid Glucosides of Scrophularia buergeriana MIQ. and Paeonia albiflora PALLAS. Chem. Pharm. Bull. (Tokyo) 1972, 20, 2450-2453. [CrossRef]

26. Matsumoto, T.; Nakamura, S.; Nakashima, S.; Ohta, T.; Ogawa, K.; Fukaya, M.; Tsukioka, J.; Hasei, T.; Watanabe, T.; Matsuda, H. Neolignan and megastigmane glucosides from the aerial parts of Isodon japonicus with cell protective effects on BaP-induced cytotoxicity. Phytochemistry 2017, 137, 101-108. [CrossRef] [PubMed]

27. Vega, P.J.; Balaban, M.O.; Sims, C.A.; O'Keefe, S.F.; Cornell, J.A. Supercritical Carbon Dioxide Extraction Efficiency for Carotenes from Carrots by RSM. J. Food Sci. 1996, 61, 757-759. [CrossRef]

28. Baysal, T.; Ersus, S.; Starmans, D.A.J. Supercritical $\mathrm{CO}_{2}$ Extraction of-Carotene and Lycopene from Tomato Paste Waste. J. Agric. Food Chem. 2000, 48, 5507-5511. [CrossRef]

29. Cádiz-Gurrea, M.; Lozano-Sánchez, J.; Fernández-Ochoa, Á.; Segura-Carretero, A. Enhancing the Yield of Bioactive Compounds from Sclerocarya birrea Bark by Green Extraction Approaches. Molecules 2019, 24, 966. [CrossRef]

30. Pimentel-Moral, S.; Borrás-Linares, I.; Lozano-Sánchez, J.; Arráez-Román, D.; Martínez-Férez, A.; Segura-Carretero, A. Supercritical $\mathrm{CO}_{2}$ extraction of bioactive compounds from Hibiscus sabdariffa. J. Supercrit. Fluids 2019, 147, 213-221. [CrossRef]

31. Bimakr, M.; Rahman, R.; Taip, F.; Chuan, L.; Ganjloo, A.; Md Salleh, L.; Selamat, J.; Hamid, A. Supercritical Carbon Dioxide (SC-CO) Extraction of Catechin, Epicatechin, 2 Rutin and Luteolin from Spearmint (Mentha spicata L.) Leaves. World Appl. Sci. J. 2008, 5, 410-417.

32. Castro-Vargas, H.I.; Rodríguez-Varela, L.I.; Ferreira, S.R.S.; Parada-Alfonso, F. Extraction of phenolic fraction from guava seeds (Psidium guajava L.) using supercritical carbon dioxide and co-solvents. J. Supercrit. Fluids 2010, 51, 319-324. [CrossRef]

33. Junior, M.R.M.; Leite, A.V.; Dragano, N.R.V. Supercritical Fluid Extraction and Stabilization of Phenolic Compounds From Natural Sources-Review (Supercritical Extraction and Stabilization of Phenolic Compounds). Open Chem. Eng. J. 2014, 5, 51-60. [CrossRef]

34. Tyśkiewicz, K.; Konkol, M.; Rój, E. Supercritical Carbon Dioxide $\left(\mathrm{scCO}_{2}\right)$ Extraction of Phenolic Compounds from Lavender (Lavandula angustifolia) Flowers: A Box-Behnken Experimental Optimization. Molecules 2019, 24, 3354. [CrossRef] [PubMed] 
35. Pinto, D.; de la LuzCádiz-Gurrea, M.; Sut, S.; Ferreira, A.S.; Leyva-Jimenez, F.J.; Dall'Acqua, S.; Segura-Carretero, A.; Delerue-Matos, C.; Rodrigues, F. Valorisation of underexploited Castanea sativa shells bioactive compounds recovered by supercritical fluid extraction with $\mathrm{CO}_{2}$ : A response surface methodology approach. J. $\mathrm{CO}_{2}$ Util. 2020, 40, 101194. [CrossRef]

36. Roselló-Soto, E.; Barba, F.J.; Lorenzo, J.M.; Dominguez, R.; Pateiro, M.; Mañes, J.; Moltó, J.C. Evaluating the impact of supercritical- $\mathrm{CO}_{2}$ pressure on the recovery and quality of oil from "horchata" by-products: Fatty acid profile, $\alpha$-tocopherol, phenolic compounds, and lipid oxidation parameters. Food Res. Int. 2019, 120, 888-894. [CrossRef] [PubMed]

(C) 2020 by the authors. Licensee MDPI, Basel, Switzerland. This article is an open access article distributed under the terms and conditions of the Creative Commons Attribution (CC BY) license (http://creativecommons.org/licenses/by/4.0/). 